\title{
Analisis Indikator Ketimpangan Gender dan Relevansinya terhadap Pertumbuhan Ekonomi Inklusif di Indonesia
}

\author{
Nadila Dwi Adika ${ }^{1 *}$, Farida Rahmawati ${ }^{2}$ \\ ${ }^{1) 2)}$ Economics and Development Study, Faculty Of Economics and Business, Universitas Negeri Malang, \\ Malang City, Indonesia \\ *E-mail corresponding author: nadilaadika@gmail.com
}

Received: 31-08-2021;

Accepted: 23-10-2021;

Available online: 31-10-2021

\section{Ecoplan}

Vol. 4 No. 2, Oktober 2021, hlm 151-162

\section{ISSN p: 2620-6102 e: $2615-5575$}

Abstract - There are biological differences between men and women, but culture interprets biological differences as creating social demands for appropriate behavior, affecting rights, resources, and powers. This discrimination is called gender inequality, and it still occurs in Indonesian's lives' aspect. At the same time, equality and the decline of inequality are indicators of inclusive economic growth in Indonesia, according to the Inclusive Economic Development Index (IPEI). Therefore, this research aims to know how indicators of gender inequality, namely, Life Expectancy (AHH), Average Length of School Term (RLS), and Expenditure Per Capita of women, will influence IPEI than Life Expectancy (AHH), Average Length of School Term (RLS) and Expenditure Per Capita of men. This research uses secondary data in the form of panel data from online publications of the National Statistic Center Agency (BPS) and National Development Planning Agency (BAPPENAS) with the research method of multiple linear regression analysis using eviews software. The result obtained $A H H$ with the probability of 0.0089, RLS with the probability of 0.0059, and women's Per Capita Expenditure with the probability of 0.0000 positively and significantly affect IPEI while only men's Per Capita Expenditure with the probability of 0.0000 has a positive and significant effect on IPEI at an alpha of 0.01. Consequently, the increase of women's independent variable has a significant and positive impact on IPEI surge compared to the increase of men's variable.
Keywords: Average Length of School (RLS), Gender Inequality, Inclusive Economic Growth, Life Expectancy Rate (AHH), Per Capita Expenditure.

Abstrak - Terdapat perbedaan secara biologis antara laki-laki dan perempuan, namun kebudayaan di masyarakat menafsirkan perbedaan biologis tersebut menciptakan tuntutan sosial dalam kepantasan berperilaku, yang pada akhirnya akan mempengaruhi hak-hak, sumber daya, maupun kuasa. Maka disebutlah diskriminasi ini sebagai ketimpangan gender, ketimpangan gender ini masih menjadi isu yang terjadi di aspek kehidupan masyarakat Indonesia. Padahal kesetaraan dan dan berkurangnya ketimpangan merupakan indikator dalam menentukan pertumbuhan ekonomi inklusif di Indonesia yang ditunjukkan berdasarkan Indeks Pembangunan Ekonomi Inklusif (IPEI). Maka dilakukan penelitian ini dengan tujuan untuk mengetahui bagaimana indikator ketimpangan gender yaitu Angka Harapan Hidup (AHH), RataRata Lama Sekolah (RLS) dan Pengeluaran Perkapita dari perempuan akan berpengaruh pada IPEI daripada Angka Harapan Hidup (AHH), Rata-Rata Lama Sekolah (RLS) dan Pengeluaran Perkapita dari laki-laki. Dalam penelitian ini digunakan data sekunder dalam bentuk data panel bersumber dari publikasi online Badan Pusat Statistik Nasional (BPS) dan Badan Perencanaan Pembangunan Nasional (BAPPENAS) dengan metode penelitian menggunakan analisisis regresi linier berganda menggunakan software eviews yang diperoleh hasil bahwa AHH dengan probabilitas 0.0089, RLS dengan probabilitas 0.0059 dan Pengeluaran Perkapita dengan probabilitas 0.0000 dari perempuan berpengaruh positif dan signifikan terhadap IPEI sedangkan pada laki-laki hanya Pengeluaran Perkapita dengan probabilitas 0.0000 yang berpengaruh secara positif dan signifikan terhadap IPEI pada alpha 0.01. Sehingga apabila dibandingkan peningkatan variabel bebas dari perempuan lebih berpengaruh signifikan dan positif terhadap peningkatan IPEI dibandingkan peningkatan dari variabel laki-laki.

Kata Kunci: AHH, Ketimpangan Gender, Pertumbuhan Ekonomi Inklusif, Pengeluaran Perkapita, RLS. 


\section{PENDAHULUAN}

Berdasarkan (Sitorus, 2016) gender dijelaskan sebagai konsep dan peran dari laki-laki maupun perempuan yang tidak terikat pada perbedaan biologis, namun lebih kepada aspek sosial budaya, polotik, serta ekonomi. Pada laki-laki dan perempuan sejatinya memiliki perbedaan secara biologis, namun kebudayaan di masyarakat menafsirkan perbedaan biologis tersebut menciptakan tuntutan sosial dalam kepantasan berperilaku, yang pada akhirnya akan mempengaruhi hak-hak, sumber daya, maupun kuasa. Walaupun ukuran kepantasan ini berbeda-beda tergantung budaya dalam masyarakatnya namun masih terdapat beberapa kemiripan, misalnya tentang mengurus anak/mengurus rumah yang identic dengan perempuan. Sedangkan ketika membicarakan tugas kemiliteran akan identik pada pekerjaan laki-laki. Maka disebutlah diskriminasi ini sebagai ketimpangan gender, yang mana untuk mengubah ketidakadilan gender tersebut akan dibutuhkan waktu yang lama. Selain itu stereotip tentang diskriminasi gender seperti dijelaskan sebelumnya dapat berakibat pada posisi perempuan yang secara budaya memiliki posisi yang lebih rendah ketimbang laki-laki, sehingga pengambilan keputusan kurang mempertimbangkan kebutuhan dari perempuan yang tentunya akan mempengaruhi capaian pembangunan di Negara ini (Kementerian Pemberdayaan Perempuan dan Perlindungan Anak, 2020).

Ketimpangan gender masih menjadi isu yang terjadi dikehidupan masyarakat begitupun di Indonesia, yang mana masih terdapat gap/ketimpangan antara laki-laki dengan perempuan yang berhubungangan dengan kebutuhan dasar manusia. Kebutuhan dasar disini menyangkut aspek pekerjaan, pendidikan, hingga kesehatan. Berdasarkan (United Nation Development Programme, 2015) mengurangi ketimpangan gender (meningkatkan kesetaraan gender) merupakan salah satu dari 17 tujian Sustainable Development Goals (SDGs). Sehingga Indonesia juga memang sudah seharusnya untuk berkomitmen agar ketimpangan gender dapat segera di kurangi. Indonesia sendiri berdasarkan (World Economic Forum, 2020) menempati peringkat 85 dalam kesetaraan gender di seluruh dunia. Peringkat tersebut lebih rendah dari pada peringkat beberapa Negara Asia Tenggara lainnya yaitu Filipina peringkat 16, Singapura peringkat 54, dan Thailand peringkat 75 .

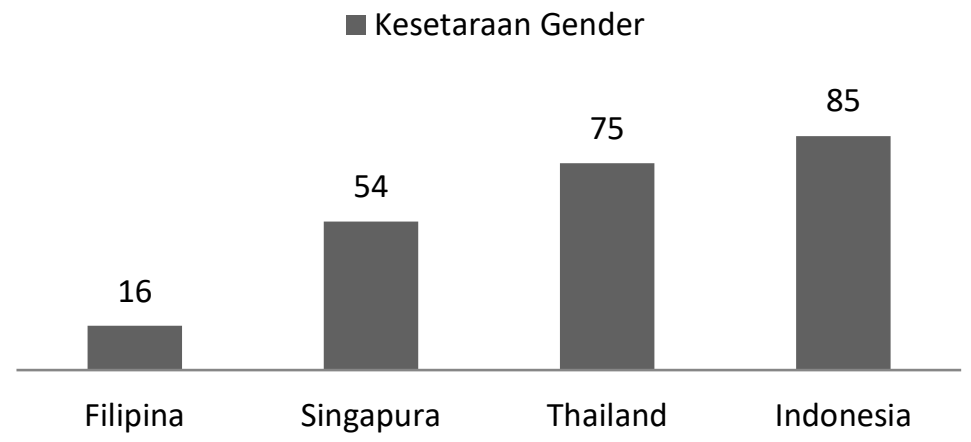

Gambar 1. Peringkat Kesataraan Gender 2020

Sumber: World Economic Forum, 2020 (data diolah)

Kondisi Ketimpangan gender di Indonesia dapat dilihat dengan cara membandingkan antara Indeks Pembangunan Gender (IPG) terhadap Indeks Pembangunan Manusia (IPM). Cara lainnya yaitu melalui nilai IPG yang mendekati angka 100 juga bearati kesetaraan gender telah terjadi, namun penting pula diikuti pula dengan kenaikan IPM. (Nazmi and Jamal, 2018). Dalam gambar 2 juga terlihat bahwa IPG di Indonesia adalah 91.06 yang berarti IPG di Indonesia masih kurang dari 100 sehingga capaian perempuan kurang dari capaian laki-laki, yang artinya masih terdapat ketimpangan gender di Indonesia seperti pada gambar 2 dibawah. Terdapat 4 indikator penting dalam membentuk Indeks Pembangunan Gender, yang mana indikator-indikator tersebut seperti indikator-indikator dalam membentuk Indeks Pembangunan Manusia. Karena antara IPG dan IPM memiliki indikator yang sama, yaitu Angka Harapan Hidup pada saat lahir (AHH), Harapan Lama Sekolah (HLS), Rata-rata lama sekolah (RLS), dan pengeluaran perkapita. Yang membedakan adalah IPM secara umum, IPG melihat secara khusus yaitu terbagi anata laki-laki dan perempuan (Badan Pusat Statistik). Menurunkan ketimpangan gender merupakan salah satu tujuan agar terpenuhnya keadilan pada setiap individu tanpa mengenal jenis kelamin dari individu tersebut. Prinsip tersebut berkaitan dengan pertumbuhan ekonomi inklusif, pertumbuhan ekonomi yang inklusif menurut (United Nation Development Programme (UNDP), 2015) bahwa pertumbuhan ekonomi inklusif merupakan pertumbuhan ekonomi alternatif yang memiliki tujuan pada kesetaraan akses serta peluang bagi seluruh masyarakat. Sehingga sangat jelas apabila menurunkan ketimpangan gender merupakan bagian dari kesetaraan yang dimaksud UNDP. 


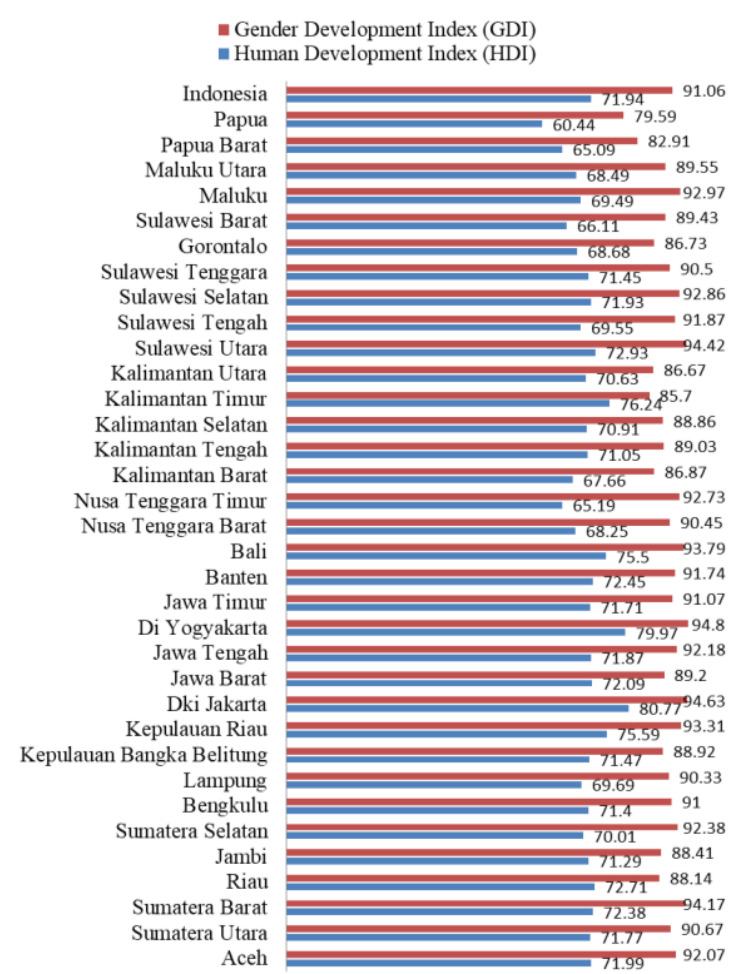

\section{Gambar 2. Perbandingan IPG terhadap IPM di Indonesia menurut Provinsi Tahun 2020}

Sumber: Badan Pusat Statistik, 2020 (data diolah)

Indonesia mengukur pertumbuhan ekonomi inklusif digunakan seatu indeks yaitu Indeks Pembangunan Ekonomi Inklusif (IPEI). IPEI dibentuk untuk mengukur tingkat inklusif dari pembangunan di Indonesia melalui aspek 3 aspek yaitu pertama pertumbuhan ekonomi, kedua ketimpangan dan kemiskinan, serta terakhir akses dan kesempatan. Sehingga indikator dalam ketimpangan gender sudah seharusnya memiliki relevansi terhadap pertumbuhan ekonomi inklusif, karena dengan meningkatnya kesetaraan gender membuktikan bahwa aspek ketimpangan serta akses dan kesempatan juga akan memperoleh dampak yang positif. Seperti yang dijelaskan oleh (Rahmawati and Hidayah, 2020) bahwa ketimpangan gender berpengaruh terhadap pertumbuhan ekonomi, yang mana dalam penelitiannya variabel bebas yang digunakan adalah AHH, RLS dan TPAK (Tingkat Partisipasi Angkatan Kerja) sedangkat variabel terikatnya adalah pertumbuhan ekonomi. Penelitian serupa juga pernah dilakukan oleh (Aktaria and Handoko, 2012) yang mana dalam penelitiannya salah satunya menggunakan Gender Inequality Index (GII) atau disebut juga indeks ketimpangan gender sebagai variabel bebas terhadap PDRB (Produk Domestik Regional Bruto) sebagai indikator Pertumbuhan Ekonomi yang mana diperoleh juga bahwa GII berpengaruh signifikan terhadap Pertumbuhan Ekonomi. Berdasarkan latar belakang dan research diatas untuk itu peneliti tertarik melakukan penelitian terkait dengan indikator dalam ketimpangan gender yang mana menggunakan indikator ketimpangan gender yang mengacu pada metodologi yang digunakan oleh (Badan Pusat Statistik, 2010) yaitu AHH, RLS, HLS, dan Pengeluaran Per Kapita. Namun dalam penelitian ini HLS tidak dijadikan variabel bebas dikarenakan HLS merupakan salah satu indikator dalam Indeks Pembangunan Ekonomi Inklusif (IPEI) sebagai indikator dari Pertumbuhan Ekonomi Inklusif di Indonesia Untuk itu diangkatlah judul tentang "Analisis Indikator Ketimpangan Gender dan Relevansinya terhadap Pertumbuhan Ekonomi Inklusif di Indonesia".

\section{TINJAUAN PUSTAKA}

\section{Ketimpangan Gender}

Kesetaraan gender (gender equality) sangat penting, karena kesetaraan gender disini memperlihatkan apabila perempuan dan lelaki menikmati status yang sama. Dengan kata lain dengan melalui kesetaraan gender ini akan mengurangi adanya ketimpangan gender (Sitorus, 2016). Menurut (Arora, 2012) definisi ketimpangan gender adalah sebagai "kumpulan masalah yang berbeda dan saling terikat". Dimana menurutnya kumpulan masalah disini dapat berupa ketimpangan dalam kematian, ketidakadilan dalam kelahiran, ketimpangan fasilitas, akses pendidikan yang tidak merata, pelatihan profesional, dll. Ketidakadilan profesional dalam pekerjaan tertentu, ketidakadilan dalam kepemilikan aset, dan 
ketidakadilan dalam rumah tangga, ketidaksetaraan gender juga ada di angkatan kerja. Jadi, ketidaksetaraan gender adalah tentang akses perempuan dalam pendidikan dan kesehatan, maupun pada pekerjaan.

\section{Pertumbuhan Ekonomi Inklusif}

Suatu peningkatan perekonomian dalam memproduksi barang-barang dan jasa-jasa merupakan definisi dari pertumbuhan ekonomi. Namun, walaupun pertumbuhan ekonomi tinggi tidak serta-merta membawa manfaat yang sama besarnya terhadap semua masyarakat (Hapsari, 2019). Sehingga beberapa lembaga internasional seperti World Economic Forum (WEF), United Nation Development Programme (UNDP), dan Asian Development Bank (ADB) menciptakan suatu formula untuk melakukan pengukuran pertumbuhan ekonomi alternative, yang akhirnya dinamakan pertumbuhan ekonomi inklusif. Menurut ADB dalam (Anand et al, 2013), pertumbuhan ekonomi inklusif penting dilakukan dengan alasan bahwa harus menjangkau seluruh lapisan masyarakat dan daerah karena terdapat kekhawatiran bahwa pertumbuhan yang memiliki ketimpangan didalamnya akan berbahaya bagi kondisi sosial, ketimpangan akses mengurangi potensi pertumbuhan yang berkelanjutan. (Purwanti and Rahmawati, 2021) juga menjelaskan bahwa pertumbuhan dikatakan inklusif apabila tidak mendeskriminasi dan menjamin pemerataan. Di Indonesia berdasarkan (Kementerian PPN/BAPPENAS, 2018) menjelaskan bahwa untuk mengukur pembangunan ekonomi inklusif di Indonesia digunakan Indeks Pembangunan Ekonomi Inklusif (IPEI) sebagai alat untuk mengukur pertumbuhan inklusif melalui banyak sektor serta mulai level kabupaten/kota maupun nasional.

Hubungan Ketimpangan Gender terhadap Pertumbuhan Ekonomi Inklusif

Menurut (Tambunan, 2016) menjelaskan bahwa terdapat 34 indikator dalam pembangunan inklusif, dimana dapat direduksi menjadi 7 indikator kunci yang mewakili semua dimensi. Dari ketujuh indikator, salah satunya adalah Kesetaraan gender. Yang mana penjelasan diatas sesuai dengan (Cabeza-García, Del Brio and Oscanoa-Victorio, 2018) menjelaskan bahwa Pertumbuhan ekonomi inklusif dilakukan dengan adanya kontribusi dari seluruh lapisan masyarakat tanpa pengecualian. (Kementerian Pemberdayaan Perempuan dan Perlindungan Anak bersama Badan Pusat Statistik, 2016) menjelaskan bahwa ketimpangan/ketidaksetaraan gender atau indeks ketimpangan gender (IPG) digunakan untuk menunjukkan masih adanya kesenjangan gender pada berbagai aspek seperti kesehatan, pendidikan, maupun ketenaga kerjaan. Di Indonesia dalam mengungkapkan ketimpangan gender biasanya menggunakan Indeks Pembangunan Gender (IPG), terdapat 4 indikator dalam IPG yaitu:

a. AHH: dalam mewakili dimensi umur panjang ataupun hidup sehat digunakanlah AHH. AHH diartikan sebagai perkiraan lama hidup seseorang sejak lahir (Hapsari, 2019).

b. RLS: RLS merupakan rata-rata jumlah tahun yang dihabiskan oleh penduduk yang beusia 25 tahun keatas dalam menyelesaikan jenjang pendidikan formal (Hapsari, 2019).

c. HLS: HLS diartikan sepagal lamanya sekolah yang diharapkan dapat ditempuh oleh anak umur pada tertentu dimasa yang akan dating. Namun HLS tidak diikutsertakan dalam variabel bebas dikarenakan HLS merupakan salah satu indikator pembentuk Indeks Pembangunan Ekonomi Inklusif (IPEI), sehingga sudah pasti memiliki pengaruh terhadap IPEI.

d. Pengeluaran Perkapita: Penghitungan pengeluaran perkapita menggunakan penyesuaian dari rata-rata pengeluaran perkapita konstan/rill terhadap paritas daya beli dengan menggunakan basis forumula Rao. Perhitungan paritas daya beli dengan menggunakan 96 komodias yang mana 66 diantaranya adalah komoditas pangan (Fridarahma, 2015).

\section{METODE PENELITIAN}

Metode yang dipilih dalam melakukan penelitian ini adalah Metode kuantitatif deskriptif, dengan metode ini dapat menggunakan teori terdahulu sehingga meneliti objek secara lebih nyata guna membuktikan hasil penelitian yang telah lebih dahulu dilakukan sebelumnya sehingga dapat membuktikan bahwasannya diduga terdapat relevansi antara variabel bebas (AHH, RLS, dan Pengeluaran Perkapita) terhadap variabel terikat (Indeks Pembangunan Ekonomi Inklusif (IPEI)).

Jenis dan Sumber Data

Jenis data sekunder dalam bentuk data panel digunakan dalam penelitian ini, dan bersumber dari publikasi online Badan Pusat Statistik Nasional dan memilih populasi AHH laki-laki serta perempuan tahun 20152020, RLS laki-laki serta perempuan tahun 2015-2019, dan Pengeluaran Perkapita laki-laki serta perempuan tahun 2015-2020. Sedangkan untuk variabel IPEI 2015-2020 menggunakan data sekunder yang bersumber pada BAPPENAS dan digunakan sebagai variabel terikat. Sehingga penelitian ini menggunakan 
sampel sebanyak 204 untuk regresi data perempuan dan 204 untuk data laki-laki, yaitu data dari 34 provinsi pada 6 tahun.

Metode Analisis Data

Analisis data dalam penelitian ini adalah metode analisisis regresi linier berganda dengan menggunakan Software Eviews. Dengan persamaan regresi sebagai berikut:

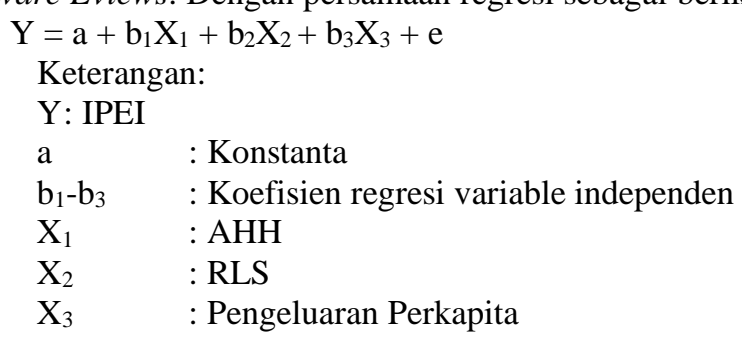

Metode Estimasi Model Regresi Panel

Dalam model regresi data panel dilakukan melalui 3 model (Basuki, A. T. and Prawoto, 2016), antara lain: Commont Effects Model, Fixed Effects Model, dan juga Random Effects Model.

\section{HASIL DAN PEMBAHASAN}

Uji Chow $($ CEM $><$ FEM)

Tabel 1 Hasil Penentuan Model Regresi dengan Uji Chow

\begin{tabular}{cccccc}
\hline Effects Test & d.f. & \multicolumn{2}{c}{ Perempuan } & \multicolumn{2}{c}{ Laki-Laki } \\
\cline { 2 - 5 } & & Statistic & Prob & Statistic & Prob \\
Cross-section F & $(33,167)$ & 17.339210 & 0.0000 & 22.671349 & 0.0000 \\
Cross-section Chi-square & 33 & 303.463561 & 0.0000 & 347.024217 & 0.0000 \\
\hline
\end{tabular}
maka berarti $\mathrm{H}_{1}$ diterima, dan digunakan model Fixed Effect Model.

Uji Hausman (FEM $><$ REM)

Tabel 2. Hasil Penentuan Model Regresi dengan Uji Hausman

\begin{tabular}{cccccc}
\hline Test Summary & Chi-Sq d.f & \multicolumn{2}{c}{ Perempuan } & Laki-Laki \\
\cline { 3 - 6 } & & Chi-Sq Statistic & Prob & Chi-Sq Statistic & Prob \\
Cross section F & 3 & 8.567781 & 0.0356 & 12.115897 & 0.0070 \\
\hline Berdasarkan table di atas, nilai probabilitas Chi Square Perempuan sebesar $0.0356>0.01$ maka \\
berarti $\mathrm{H}_{0}$ diterima, dan digunakan & model & Random & Effect & Model. Sedangkan pada laki-laki nilai \\
probabilitas Chi Square sebesar $0.0070<0.01$ maka berarti $\mathrm{H}_{1}$ diterima, dan digunakan model Fixed Effect \\
Model. Dari hasil uji chow dan uji hausman disimpulkan menggunakan model yang berbeda.
\end{tabular}

Uji Multikolinieritas

Tabel 3. Hasil Uji Multikolinieritas (Perempuan)

\begin{tabular}{cccc}
\hline & Ln AHH & Ln RLS & Ln Pengeluaran Perkapita \\
Ln AHH & 1.000000 & 0.405667 & 0.466620 \\
Ln RLS & 0.405667 & 1.000000 & 0.498738 \\
Ln Pengeluaran Perkapita & 0.466620 & 0.498738 & 1.000000 \\
\hline & Tabel 4. Hasil Uji Multikoliniaritas (Laki-Laki) \\
\hline Ln AHH & Ln AHH & Ln RLS & Ln Pengeluaran Perkapita \\
Ln RLS & 1.000000 & 0.381221 & 0.593497 \\
Ln Pengeluaran Perkapita & 0.381221 & 1.000000 & 0.443671 \\
& 0.593497 & 0.443671 & 1.000000 \\
\hline
\end{tabular}


Pada tabel 3 dan 4 di atas menjelaskan bahwa nilai koefisien relasi $<0,8$ maka berarti dalam data tersebut tidak terjadi multikolineritas, segungga tidak terjadi korelasi antar variabel.

\section{Uji Heteroskedastisitas}

Tabel 5. Hasil Uji Heteroskedastisitas

\begin{tabular}{ccc}
\hline Variable & Prob. Perempuan & Prob. Laki-Laki \\
C & 0.7358 & 0.0903 \\
Ln AHH & 0.8022 & 0.0833 \\
Ln RLS & 0.5965 & 0.6385 \\
Ln Pengeluaran Perkapita & 0.1154 & 0.2762 \\
\hline
\end{tabular}

Uji heteroskedastisitas bertujuan untuk mengetahui ketidaksamaan varian yang biasanya disebut heteroskedastisitas. Yang mana agar dipastikan bahwa varians dari residual diatas bersifat homoskedastisitas. Pada tabel 5 diatas dapat terlihat bahwa probabilitas dari masing-masing variabel independen diatas alpha $(\alpha) 0.01$.

\section{Hasil Regresi Data Perempuan (Random Effect Model)}

Tabel 6. Hasil Regresi Data Perempuan (Random Effect Model)

\begin{tabular}{|c|c|c|}
\hline Variable & Coefficient & Prob. \\
\hline $\mathrm{C}$ & -4.671412 & 0.0002 \\
\hline Ln $\mathrm{AHH}$ & 0.840794 & 0.0089 \\
\hline Ln RLS & 0.200282 & 0.0059 \\
\hline Ln Pengeluaran Perkapita & 0.265593 & 0.0000 \\
\hline R-squared & \multicolumn{2}{|c|}{0.457585} \\
\hline F-statistic & \multicolumn{2}{|c|}{56.24047} \\
\hline Prob(F-statistic) & \multicolumn{2}{|c|}{0.000000} \\
\hline
\end{tabular}

Selain cara diatas dapat juga dilihat melalui t-hitung dan t-tabel.Hal ini dapat dilakukan dengan ketentuan apabila t-hitung > t-tabel maka terdapat pengaruh begitu pula sebaliknya. Nilai t-tabel ditentukan dengan penghitungan dalam rumus berikut:

$$
\begin{aligned}
& \mathrm{t} \text {-tabel }=\mathrm{t}(\alpha / 2 ; \mathrm{n}-\mathrm{k}-1)=\mathrm{t}(0,01 / 2 ; 204-3-1) \\
& \quad=\mathrm{t}(0,005 ; 200)=2.60063
\end{aligned}
$$

Dimana $\alpha$ adalah tingkat kepercayaan $99 \%$ yaitu 0.01 atau signifikan pada $1 \%$. Sehingga diperoleh nilai t-tabel sebesar 2.60063, nilai tersebut dapat dilihat pada t-tabel dengan kolom 0.005 dan baris ke-200 Persamaan regresinya dapat dituliskan sebagai berikut:

$$
I P E I=-4.67141+0.84079_{A H H}+0.20028_{R L S}=0.26559_{\text {PENGELUARAN PERKAPITA }}
$$

Nilai R-squared menunjukkan angka sebesar 0.457585 atau sebesar $45.76 \%$ sehingga dapat disimpulkan bahwa Indeks Pembangunan Ekonomi Inklusif (Y) dapat dijelaskan oleh AHH Perempuan (X1), RLS Perempuan (X2), dan Pengeluaran Perkapita Perempuan (X4) sebesar 45.76\% dan 54.24\% dipengaruhi oleh variabel lain.

a. Nilai probabilitas variabel AHH Perempuan sebesar 0.0089 dan memiliki koefisien sebesar 0.840794 yang bernilai positif, sehingga ketika AHH Perempuan mengalami peningkatan sebesar 1 satuan maka akan menaikkan IPEI sebesar 0.840794 satuan.

b. Nilai probabilitas variabel RLS Perempuan sebesar 0.0059 dan memiliki koefisien sebesar 0.200282 yang bernilai positif, sehingga ketika RLS Perempuan mengalami peningkatan sebesar 1 satuan maka akan menaikkan IPEI sebesar 0.200282 satuan.

c. Nilai probabilitas variabel Pengeluaran Perkapita Perempuan sebesar 0.0000 dan memiliki koefisien sebesar 0.265593 yang bernilai positif, sehingga ketika Pengeluaran Perkapita Perempuan mengalami peningkatan sebesar 1 satuan maka akan meningkatkan IPEI sebesar 0.265593 satuan.

d. Berdasarkan uji simultan (uji F) pada signifikansi 1\% dengan nilai probabilitas sebesar 0.000000 $<0.01$, yang berarti variabel AHH Perempuan (X1), RLS Perempuan (X2), dan Pengeluaran Perkapita Perempuan (X3) berpengaruh secara simultan terhadap IPEI (Y). Dalam uji parsial (uji t) pada signifikansi $1 \%$ dapat disimpulkan bahwa variabel AHH Perempuan (X1), RLS Perempuan 
(X2), dan Pengeluaran Perkapita Perempuan (X3) berpengaruh secara parsial terhadap variabel IPEI (Y). Dapat pula dilakukan dengan cara membandingkan antara F-hitung dan F-tabel, ketika $\mathrm{F}$ hitung $>$ dari $\mathrm{F}$ tabel maka variabel independen memmengaruhi variabel dependen begitu pula sebaliknya. F tabel dalam penelitian ini dapat dihitung dengan menggunakan rumus sebagai berikut:

$$
\begin{aligned}
\mathrm{F} \text { tabel } & =\mathrm{F}(\mathrm{k} ; \mathrm{n}-\mathrm{k})=\mathrm{F}(3 ; 204-3) \\
& =\mathrm{F}(3 ; 201)=2.65
\end{aligned}
$$

Dimana k: jumlah variabel independen dan $\mathrm{n}$ : jumlah sampel dalam penelitian. Nilai $\mathrm{F}$ tabel dapat dilihat melalui $\mathrm{F}$ tabel dengan kolom ke-3 dan baris ke-201. Berdasarkan hasil uji regresi pada tabel 6, terlihat nilai $\mathrm{F}$ hitung $>\mathrm{F}$ tabel dimana $56.24>2.65$.

Hasil Regresi Data Laki-Laki (Fixed Effect Model)

Tabel 7. Hasil Regresi Data Laki-Laki (Fixed Effect Model)

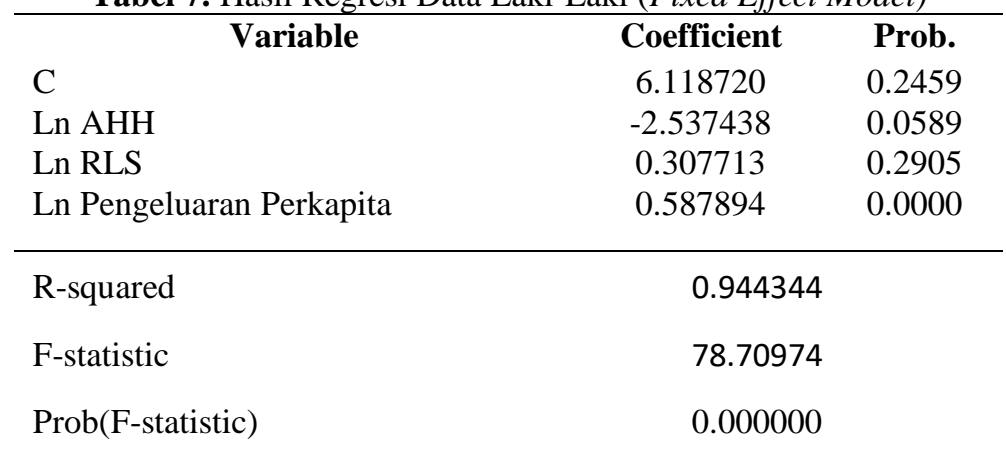

Untuk uji t sama dengan yang terdapat pada regresi data perempuan sehingga nilai $t$ tabel juga sama yaitu sebesar 2.60063 .

Persamaan regresinya dapat dituliskan sebagai berikut:

$P E I=6.11872+(-2.53743)_{A H H}+0.30771_{\text {RLS }}+0.58789_{\text {PENGELUARAN PERKAPITA }}$

Nilai $R$-squared menunjukkan angka sebesar 0.944344 atau sebesar $94.43 \%$ sehingga dapat disimpulkan bahwa Indeks Pembangunan Ekonomi Inklusif (Y) dapat dijelaskan oleh AHH Laki-Laki (X1), RLS Laki-Laki (X2), dan Pengeluaran Perkapita Laki-Laki (X3) sebesar 94.43\% dan 5.57\% dipengaruhi oleh variabel lain.

a. Nilai probabilitas variabel AHH Laki-Laki sebesar 0.0589 dan memiliki koefisien sebesar -2.537438 yang bernilai negatif, sehingga ketika AHH Laki-Laki meningkat sebesar 1 satuan maka akan menurunkan IPEI sebesar 2.537438 satuan.

b. Nilai probabilitas variabel RLS Laki-Laki sebesar 0.2905 dan memiliki koefisien sebesar 0.307713 yang bernilai positif, sehingga ketika RLS Laki-Laki mengalami peningkatan sebesar 1 satuan maka akan menaikkan IPEI sebesar 0.307713 satuan.

c. Nilai probabilitas variabel Pengeluaran Perkapita Laki-Laki sebesar 0.0000 dan memiliki koefisien sebesar 0.587894 yang bernilai positif, sehingga ketika Pengeluaran Perkapita Laki-Laki mengalami peningkatan sebesar 1 satuan maka akan meningkatkan IPEI sebesar 0.587894 satuan.

d. Berdasarkan uji simultan (uji F) pada signifikansi 1\% dengan nilai probabilitas sebesar $0.000000<$ 0.01, maka berarti variabel AHH Laki-Laki (X1), RLS Laki-Laki (X2), dan Pengeluaran Perkapita Laki-Laki (X3) berpengaruh secara simultan terhadap IPEI (Y). Dalam uji parsial (uji t) pada signifikansi $1 \%$ dapat disimpulkan bahwa variabel Pengeluaran Perkapita Laki-Laki (X3) berpengaruh secara parsial terhadap variabel IPEI Laki-Laki (Y), sedangkan variabel AHH LakiLaki (X1) dan RLS Laki-Laki (X2) tidak memiliki pengaruh. Dengan ketentuan yang sama sebagaimana pada regresi data perempuan pada data laki-laki juga memiliki nilai $\mathrm{F}$ tabel yang sama yaitu 2.65. Berdasarkan hasil uji regresi pada tabel 7, bahwa nilai $\mathrm{F}$ hitung $>\mathrm{F}$ tabel dimana 78.71 $>2.65$.

Relevansi AHH Perempuan maupun Laki-Laki yang terhadap Pertumbuhan Ekonomi Inklusif di Indonesia

Pada AHH perempuan dan AHH laki-laki memiliki kesimpulan hasil regresi yang berbeda. Yang mana ketika AHH perempuan berpengaruh positif dan signifikan terhadap IPEI di Indonesia, maka terjadi keadaan yang berbeda pada AHH laki-laki yang tidak berpengaruh signifikan terhadap IPEI di Indonesia. Koefisien variabel AHH perempuan sebesar 0.850642 dengan probabilitas 0.0089 menjelaskan bahwa setiap peningkatan satu-satuan AHH perempuan maka dapat meningkatkan IPEI sebesar 0.850642 satu- 
satuan. Hal ini berarti jika AHH perempuan mengalami peningkatan maka IPEI juga akan mengalami peningkatan karena memiliki pengaruh yang positif. Dari data diatas terlihat bahwa apabila dibandingkan peningkatan AHH perempuan lebih berpengaruh signifikan terhadap IPEI jika dibandingkan dengan AHH laki-laki

Ketika berbicara tentang AHH tentu sama dengan membicarakan keadaan kesehatan, khususnya di Indonesia. Yang mana dengan melalui hasil regresi yang telah dilakukan dapat terlihat bahwa kesetaraan dalam bidang kesehatan ikut andil dalam pertumbuhan ekonomi inklusif di Indonesia. Hasil yang sama juga diperoleh (Rahmawati and Hidayah, 2020), yang mana dalam penelitiannya diperoleh hasil bahwa AHH memiliki pengaruh yang positif serta signifikan terhadap pertumbuhan ekonomi dengan koefisien sebesar 1.456397 serta memiliki probabilitas sebesar 0.001. Walaupun variabel dependen yang digunakan berbeda yaitu variabel pertumbuhan ekonomi namun jika melihat pada (Kementerian PPN/BAPPENAS, 2018) dijelaskan bahwa pertumbuhan ekonomi lebih tinggi sangat diperlukan sebagai salah satu syarat dalam pembangunan ekonomi yang inklusif. Sehingga menurut (Rahmawati \& Hidayah, 2020) dalam penelitiannya berasumsi bahwa harapan hidup yang semakin tinggi dapat diartikan sebagai peningkatan terbuka nya kesempatan bagi perempuan dalam kontribusinya dibidang perekonomia. Selain itu AHH perempuan yang signifikan terhadap IPEI, sedangkan AHH laki-laki tidak signifikan dapat dikarenakan pada data yang diregresi yaitu AHH perempuan dan laki-laki pada tahun 2015-2020 menunjukkan bahwa AHH perempuan lebih besar ketimbang laki-laki sehingga AHH perempuan akan memiliki pengaruh yang signifikan terhadap laki-laki.

$\square$ AHH Perempuan $\square$ AHH Laki-Laki

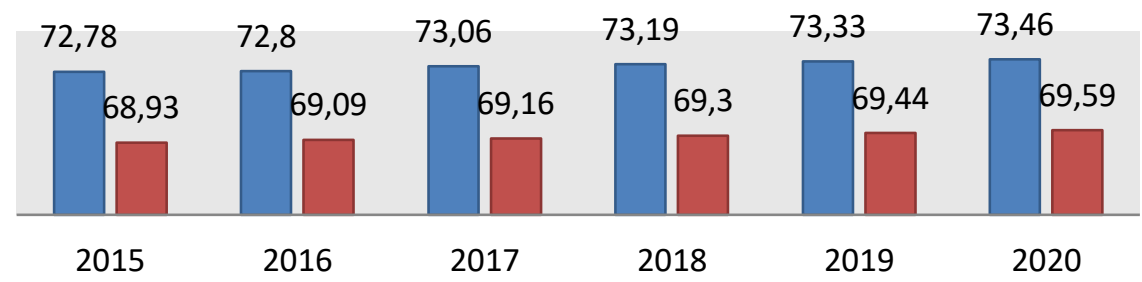

Gambar 3. Perbandingan AHH Perempuan dan Laki-Laki di Indonesia 2015-2020

Sumber: Badan Pusat Statistik, 2020 (data diolah)

Dari hasil regresi tentu dapat terlihat bahwa AHH perempuan memiliki pengaruh yang signifikan sedangkan disbanding dengan AHH laki-laki yang tidak signifikan terhadap variabel IPEI. Sehingga melalui penelitian ini AHH perempuan akan lebih baik jika terus meningkat karena selain memiliki pengaruh yang positif dan signifikan namun juga dapat meningkatkan IPG yang berarti ketimpangan gender semakin berkurang. Berdasarkan (Kementerian Perencanaan Pembangunan Nasional, 2015) pada Rencana Pembangunan Jangka Menengah Nasional (RPJMN) 2015-2019 dijelaskan bahwa terdapat beberapa indikator dalam meningkatkan AHH perempuan, salah satunya dapat terlihat dari Angka Kematian Ibu (AKI). AKI di Indonesia pada tahun 2019 berdasarkan (Susiana, 2019) yang dipublikasikan atas nama Pusat Penelitian Badan Keahlian DPR RI menjelasakan bahwa pada tahun 2019 AKI di Indonesia masih tinggi 305 per 100.000 kelahiran hidup, yang berada di tiga kali lipat lebih rendah dari targetnya yaitu 102 per 100.000 kelahiran hidup. Selain itu terdapat pula indikator lain seperti status kesehatan dan gizi, Angka Kematian Balita (AKBa) sampai dengan Kasus HIV-AIDS yang dialami oleh ibu rumah tangga yang juga dapat mempengaruhi keberhasilan peningkatan AHH di Indonesia. Untuk itu telah dibuat kebijakan serta strategi untuk meningkatkan kesehatan sumber daya manusia yang tertuang pada (RPJMN 2020-2024, 2020)) salah satunya melalui program peningkatan kesehatan ibu dan anak serta Keluarga Berencana (KB) dan kesehatan reproduksi yang merupakan poin pertama pada strategi peningkatan akses dan pelayanan kesehatan. Sebagaimana pada Gambar 3 yang menunjukkan bahwa pada lima tahun terakhir AHH perempuan maupun laki-laki sama-sama mengalami kenaikan. Walaupun nilai penambahannya sama-sama tidak besar baik pada AHH perempuan maupun laki-laki. Namun tetap saja peningkatan AHH tersebut telah membuktikan bahwa Indonesia juga sedang berusaha memperbaiki kualitas kesehatan di Indonesia agar lebih baik. Dikarenakan AHH yang cenderung semakin meningkat pada perempuan dan laki-laki, untuk itu perlunya kebijakan maupun program pembangunan yang memfasilitasi bagi kelompok lanjut usia (lansia) yang tentunya sangat perlu diperhatikan apabila mengingat keadaan bertambahnya AHH. Dalam (Tambunan, 2016) menambahkan bahwa dalam meningkatkan inklusifitas di sektor kesehatan sangat diperlukan kebijakan yang lebih memfokuskan pada pendidikan atau peningkatan pengetahuan di bidang kesehatan seperti kampanye hidup bersih serta gizi seimbang. 
Relevansi RLS Perempuan maupun Laki-Laki yang terhadap Pertumbuhan Ekonomi Inklusif di Indonesia

Pada RLS perempuan dan laki-laki memiliki kesimpulan hasil regresi yang berbeda. Yang mana ketika RLS perempuan berpengaruh positif serta signifikan terhadap IPEI, maka terjadi keadaan yang berbeda pada RLS laki-laki yaitu RLS laki-laki berpengaruh tidak signifikan terhadap IPEI di Indonesia. Koefisien variabel RLS perempuan sebesar 0.200282 dengan probabilitas 0.0059 menjelaskan bahwa setiap peningkatan satu-satuan RLS perempuan maka dapat meningkatkan IPEI sebesar 0.200282 satu-satuan. Hal ini berarti jika RLS perempuan mengalami peningkatan maka IPEI juga akan mengalami peningkatan karena memiliki pengaruh yang positif. Dari data diatas terlihat bahwa apabila dibandingkan peningkatan RLS perempuan lebih berpengaruh signifikan terhadap IPEI jika dibandingkan dengan RLS laki-laki.

RLS digunakan sebagai indikator dalam mengukur pencapain pendidikan di Indonesia. Yang mana dengan melalui hasil regresi yang telah dilakukan dapat terlihat bahwa kesetaraan dalam bidang pendidikan ikut andil dalam pertumbuhan ekonomi inklusif di Indonesia. Hasil penelitian ini tidak sesuai dengan hasil penelitian yang dilalakukan oleh (Vininda and Yuliana, 2015) yang mana dalam penelitian tersebut diperoleh hasil bahwa pada rata-rata lama sekolah perempuan berpengaruh tidak signifikan dan negatif terhadap PDRB, PDRB sendiri merupakan salah satu indikator dalam pertumbuhan ekonomi sedangkan pertumbuhan ekonomi merupakan salah satu sub pilar dalam Indeks Pembangunan Ekonomi Inklusif. Menurut penelitiannya hubungan negatif antara RLS dan PDRB di Provinsi Riau terjadi dikarenakan kecenderungan dari PDRB yang meningkat namun RLS tampak menurun. Sedangkan dalam penelitian ini terjadi hubungan signifikan positif antar RLS dan IPEI, yang mana hal tersebut dapat terjadi karena RLS yang selalu mengalami peningkatan sebagaimana pula yang terjadi pada IPEI. Namun pada penelitian yang dilakukan oleh (Rahmawati \& Hidayah, 2020) diperoleh hasil bahwa rasio lama sekolah memiliki pengaruh yang positif serta signifikan terhadap pertumbuhan ekonomi di Provinsi Jawa Timur.

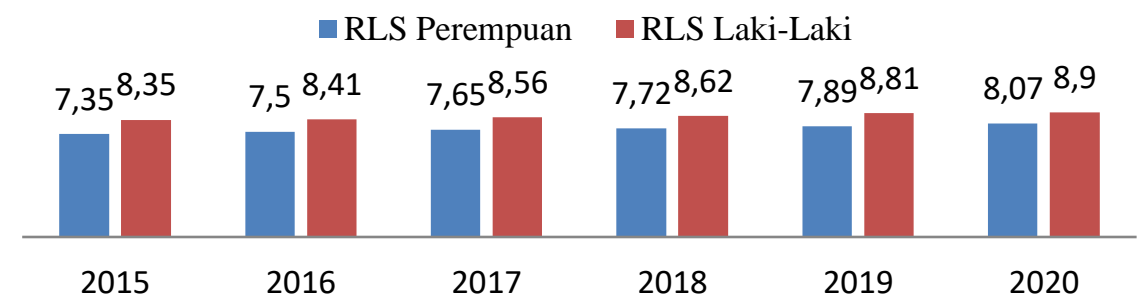

Gambar 4. Perbandingan RLS Perempuan dan Laki-Laki di Indonesia 2015-2020

Sumber: Badan Pusat Statistik, 2020 (data diolah)

Pada gambar 4 diatas telah menggambarkan masih terjadi kesenjangan pada sektor pendidikan antara perempuan yang lebih rendah daripada laki-laki di Indonesia, padahal menurut hasil regresi yang telah dilakukan dalam penelitian ini diperoleh bahwa RLS perempuan memiliki pengaruh yang signifikan serta positif terhadap IPEI di Indonesia. Sehingga sudah seharusnya peningkatan RLS perempuan dilakukan, karena tidak hanya akan berpengaruh pada IPEI namun juga sebagai upaya agar kesetaraan dalam pendidikan juga tercapai sebagaimana menurut (Kementerian Pemberdayaan Perempuan dan Perlindungan Anak, 2020) dalam publikasinya yang berjudul Pembangunan Manusia Berbasis Gender 2020 menyebutkan bahwa "Lama Sekolah Perempuan Masih Perlu Ditingkatkan". Peningkatan RLS perempuan pada dasarnya sangat membawa dampak positif bagi pertumbuhan ekonomi, misalnya dalam penjelasan (Sitorus, 2016) yang menyebutkan setidaknya terdapat empat alasan yang menjadikan pendidikan perempuan mempengaruhi pertumbuhan ekonomi. Empat alasan tersebut adalah pada Negara berkembang memiliki tumbal balik dari pendidikan perempuan yang lebih tinggi ketimbanga laki-laki. Yang kedua adalah peningkatan pendidikan akan meningkatkan partisipasi tenaga kerja, mengurangi pernikahan dini, serta dampak pada kesehatan misalnya fertilitas yang lebih render dan perbaikan gizi pada anak. Yang ketiga adalah dengan adanya ibu yang terdidik dan anak yang bergizi akan memberikan dampak pengganda terhadap kualitas generasi mendatang. Dan yang terakhir adalah wanita yang terdidik dapat mempunyai dampak penting dalam jangka panjang dalam memutus lingkaran kemiskinan yang masih terjadi di Indonesia serta pendidikan yang masih belum memadai. Hal tersebut juga sama dengan penjelasan dari (Todaro and Smith, 2003) bahwa mempersempit kesenjangan gender dalam pendidikan dapat menguntungkan secara ekonomis yaitu dapat meningkatkan partisipasi tenaga kerja perempuan yang mana dapat menunda pernikahan dan mendidik anak secara lebih berkualitas. Dari hal tersebut tentu akan menciptakan generasi yang lebih cerdas sehingga kedepannya kemiskinan akan berkurang pula. 
Relevansi Pengeluaran Perkapita Perempuan maupun Laki-Laki yang terhadap Pertumbuhan Ekonomi Inklusif di Indonesia

Pada Pengeluaran Perkapita perempuan dan laki-laki memiliki kesimpulan hasil regresi yang sama. Yang mana ketika Pengeluaran Perkapita perempuan berpengaruh positif serta signifikan terhadap IPEI di Indonesia, maka terjadi keadaan yang sama pada Pengeluaran Perkapita laki-laki yaitu Pengeluaran Perkapita laki-laki berpengaruh positif serta signifikan terhadap IPEI di Indonesia. Koefisien variabel Pengeluaran Perkapita perempuan sebesar 0.265593 dengan probabilitas 0.0000 menjelaskan bahwa setiap peningkatan satu-satuan Pengeluaran Perkapita perempuan maka dapat meningkatkan IPEI sebesar 0.265593 satu-satuan. Hal ini berarti jika Pengeluaran Perkapita perempuan mengalami peningkatan maka IPEI juga akan mengalami peningkatan karena memiliki pengaruh yang positif. Sedangkan untuk variabel RLS laki-laki memiliki koefisien sebesar 0.587894 dengan probabilitas 0.0000 menjelaskan bahwa setiap peningkatan satu-satuan RLS laki-laki maka dapat meningkatkan IPEI sebesar 0.587894 satu-satuan. Dari data diatas terlihat bahwa RLS perempuan maupun laki-laki berpengaruh signifikan terhadap IPEI.

Berdasarkan regresi yang telah dilakukan, diperoleh hasil bahwasannya Pengeluaran Perkapita perempuan dan laki-laki berpengaruh signifikan terhadap IPEI. Hal tersebut sesuai dengan penelitian (Muda and dkk, 2019) yang mana diperoleh hasil regresi bahwa pengeluaran perkapita berpengaruh signifikan terhadap pertumbuhan ekonomi. Seperti telah dijelaskan sebelu-sebelumnya jika pertumbuhan ekonomi merupakan salah satu sub pilar IPEI yang ada pada (Kementerian PPN/BAPPENAS, 2020) yang mana dijelaskan pula pada (Kusumaningrum and Yuhan, 2019) bahwa dalam menyusun Indeks Komposit Pertumbuhan Inklusif (IKPI) salah satu dimensi utama yang digunakan adalah Pertumbuhan Ekonomi. Hasil yang sama diperoleh pada penelitian dari (Ayu and Faisal, 2021) yang mana dalam penelitiannya diperoleh bahwa pengeluaran perkapita berpengaruh positif serta signifikan terhadap kemiskinan di Kota Makassar, yang mana kemiskinan ini jg merupakan indikator penting dalam IPEI.

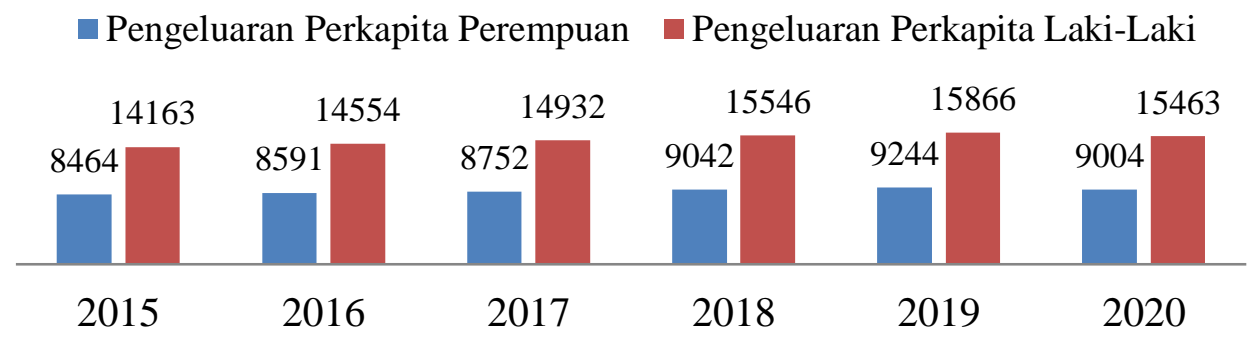

Gambar 5. Perbandingan Pengeluaran Perkapita Perempuan dan Laki-Laki di Indonesia 2015 -

Sumber: Badan Pusat Statistik, 2020 (data diolah) 2020 (Ribu Rupiah)

Dari gambar 5 diatas terlihat adanya kesenjangan dari pengeluaran perkapita yang tinggi dari perempuan dan laki-laki, Pada tahun 2020 Pengeluaran Perkapita perempuan sebesar Rp. 9.004.000/tahun sedangkan pada laki-laki sebesar Rp. 15.463.000/tahun. Dari hasil tersebut diperoleh rasio pengeluaran perkapita perempuan yang hanya sebesar 58.23 persen jika dibandingkan pengeluaran perkapita laki-laki. Berdasarkan (Kementerian Pemberdayaan Perempuan dan Perlindungan Anak, 2019) menyebutkan bahwa salah satu alasan yang menjadi sebab ketimpangan pengeluaran perkapita yang terjadi antara perempuan dan laki-laki dapat disebabkan dari ketimpangan dalam hal upah pekerja, yang mana hal tersebut dapat dikatakan tepat mengingat rata-rata upah/gaji perempuan pada tahun 2019 hanya sebesar Rp. 2.451.057, yang lebih kecil apabila dibandingkan dengan rata-rata gaji laki-laki yang sebesar Rp. 3.167.092. Selain karena upah, ketimpangan pengeluaran perkapita juga dapat dikarenakan konsumsi rokok oleh laki-laki sehingga menambah pengeluaran perkapita laki-laki ketimbang pengeluaran perkapita perempuan. Dari penjelasan tersebut guna meningkatkan IPEI melalui pengeluaran perkapita perempuan dapat dilakukan dengan meningkatkan upah rata-rata/ gaji buruh/karyawan, dan hal tersebut juga telah menjadi kebijakan dari pemerintah melalui adanya Upah Minimum sehingga dapat mengurangi ketimpangan upah bagi perempuan terhadap laki-laki.

\section{KESIMPULAN}

Berdasarkan hasil analisis penelitian mengenai relevansi dari AHH, RLS, dan Pengeluaran Perkapita Perempuan maupun Laki-Laki yang merupakan salah satu indikator dalam IPG terhadap Pertumbuhan Ekonomi Inklusif di Indonesia, diperoleh kesimpulan sebagai berikut: 
a. Pada AHH perempuan dan laki-laki memiliki kesimpulan hasil regresi yang berbeda. Yaitu ketika AHH perempuan berpengaruh signifikan dan positif terhadap IPEI di Indonesia, namun pada AHH laki-laki yaitu berpengaruh tidak signifikan terhadap IPEI di Indonesia.

b. Pada RLS perempuan dan laki-laki memiliki kesimpulan hasil regresi yang berbeda. Yaitu ketika RLS perempuan berpengaruh signifikan dan positif terhadap IPEI di Indonesia, pada RLS lakilaki berpengaruh tidak signifikan terhadap IPEI di Indonesia.

c. Pada Pengeluaran Perkapita perempuan dan laki-laki memiliki kesimpulan hasil regresi yang sama. Yaitu ketika Pengeluaran Perkapita perempuan berpengaruh signifikan positif terhadap IPEI di Indonesia, begitu pula pada Pengeluaran Perkapita laki-laki yaitu Pengeluaran Perkapita lakilaki juga sama sama berpengaruh signifikan positif terhadap IPEI di Indonesia.

\section{DAFTAR PUSTAKA}

Aktaria, E. and Handoko, B. S. (2012) 'Ketimpangan Gender Dalam Pertumbuhan Ekonomi', Jurnal Ekonomi Pembangunan: Kajian Masalah Ekonomi dan Pembangunan, 13(2), pp. 194-206. doi: 10.23917/jep.v13i2.168.

Anand et al (2013) 'Inclusive Growth Revisited: Measurement and Determinants', (122), pp. 1-7. Available at: http://citeseerx.ist.psu.edu/viewdoc/summary?doi=10.1.1.690.837.

Arora, R. U. (2012) 'Gender Inequality, Economic Development, And Globalization: A State Level Analysis of India', The Journal of Developing Areas, 46(1), pp. 147-164. Available at: https://www.jstor.org/stable/23215428?read-now=1\&seq=1\#page_scan_tab_contents.

Ayu, N. E. N. and Faisal, A. A. (2021) 'Mengukur Dampak Pengangguran, Tingkat Pendidikan, Upah Minimum, dan Pengeluaran Per Kapita Terhadap Kemiskinan di Kota Makassar', Bulletin of Economic Studies, 1(1), pp. 1-12. Available at: http://journal.uinalauddin.ac.id/index.php/best/article/view/19637/10934.

Badan Pusat Statistik (2010) Metodologi Indeks Pembangunan Gender (IPG). Available at: https://www.bps.go.id/subject/40/gender.html\#subjekViewTab2 (Accessed: 30 July 2021).

Badan Pusat Statistik (2020) Angka Harapan Hidup (AHH) Menurut Kabupaten/Kota dan Jenis Kelamin (Tahun), 2015-2020. Available at: https://www.bps.go.id/indicator/40/455/1/angka-harapan-hidupahh-menurut-kabupaten-kota-dan-jenis-kelamin.html.

Badan Pusat Statistik (2020) Indeks Pembangunan Gender dan Indeks Pembangunan Manusia. Available at: https://www.bps.go.id/indicator/40/463/1/indeks-pembangunan-gender-ipg-.html (Accessed: 27 July 2021).

Badan Pusat Statistik (2020) Pengeluaran per Kapita yang Disesuaikan menurut Jenis Kelamin (Ribu Rupiah/Orang/Tahun 2015-2020.

Available

at: https://www.bps.go.id/indicator/40/461/1/pengeluaran-per-kapita-yang-disesuaikan-menurut-jeniskelamin.html.

Badan Pusat Statistik (2020) Rata-rata Lama Sekolah (RLS) menurut Jenis Kelamin (Tahun), 2015-2020. Available at: https://www.bps.go.id/indicator/40/459/1/rata-rata-lama-sekolah-rls-menurut-jeniskelamin.html.

Basuki, A. T. and Prawoto (2016) Analisis Regresi Dalam Penelitian Ekonomi \& Bisnis : Dilengkapi Aplikasi SPSS \& EVIEWS. Depok: PT Raja Grafindo Persada.

Cabeza-García, L., Del Brio, E. B. and Oscanoa-Victorio, M. L. (2018) 'Gender factors and inclusive economic growth: The silent revolution', Sustainability (Switzerland), 10(121), pp. 1-14. doi: $10.3390 / \mathrm{su} 10010121$

Hapsari, W. R. (2019) 'Analisis Pertumbuhan Ekonomi Inklusif Kabupaten/Kota di Provinsi Jawa Tengah', JURNAL LITBANG SUKOWATI, 3(1), pp. 106-116. doi: 10.1017/CBO9781107415324.004.

Kementerian Pemberdayaan Perempuan dan Perlindungan Anak (2020) Pembnagunan Manusia Berbasis Gender 2020. Jakarta. Available at: https://www.kemenpppa.go.id/index.php/page/read/24/3060/pembangunan-manusia-berbasisgender-2020.

Kementerian Pemberdayaan Perempuan dan Perlindungan Anak bersama Badan Pusat Statistik (2016) Potret Ketimpangan Gender dalam Ekonomi. Jakarta.

Kementerian Perencanaan Pembangunan Nasional (2015) 'Rencana Pembangunan Jangka Menengah Nasional (RPJMN) 2015-2019', Kementrian Perencanaan Pembangunan Nasional. Available at: http://www.bpkp.go.id/public/upload/unit/sesma/files/Buku II RPJMN 2015-2019.pdf.

Kementerian PPN/BAPPENAS (2018) Indeks Pembangunan Ekonomi Inklusif, Badan Perencanaan Pembangunan Nasional. Available at: http://inklusif.bappenas.go.id/indeks (Accessed: 26 July 2020). 
Kusumaningrum, S. and Yuhan, R. J. (2019) 'Pertumbuhan Ekonomi Provinsi di Indonesia Berdasarkan Indeks Komposit Pertumbuhan Inklusif dan Faktor yang Memengaruhinya ( Economic Growth of Provinces in Indonesia Based on Inclusive Growth Composite Index and The Influence Factors )', Ekonomi Dan Kebijakan Publik, 10(1), pp. 1-18. Available at: http://jurnal.dpr.go.id/index.php/ekp/article/view/1150.

Muda, R. and dkk (2019) 'Pengaruh Angka Harapan Hidup, Tingkat Pendidikan Dan Pengeluaran Perkapita Terhadap Pertumbuhan Ekonomi Di Sulawesi Utara Pada Tahun 2003-2017', Jurnal Berkala Ilmiah Efisiensi, 19(01), pp. Available 44-55. https://ejournal.unsrat.ac.id/index.php/jbie/article/view/22368/22050.

Nazmi, L. and Jamal, A. (2018) 'Pengaruh Ketimpangan Gender terhadap Pertumbuhan Ekonomi di Indonesia’, 3(4), pp. 740-750. Available at: http://jim.unsyiah.ac.id/EKP/article/view/10627.

Purwanti, S. D. and Rahmawati, F. (2021) 'Pengaruh Pengeluaran Pemerintah Dan Tingkat Pengangguran Terbuka (TPT) Terhadap Pertumbuhan Ekonomi Inklusif Indonesia’, Ecoplan, 4(1), pp. 32-44. doi: 10.20527/ecoplan.v4i1.231.

Rahmawati, F. and Hidayah, Z. M. (2020) 'Menelusur Relasi Indeks Pembangunan Gender Terhadap Pertumbuhan Ekonomi', EcceS (Economics, Social, and Development Studies), 7(1), p. 110. doi: 10.24252/ecc.v7i1.13919.

RPJMN 2020-2024 (2020) Rencana Pembangunan Jangka Menengah Nasional 2020-2024. Available at: https://www.bappenas.go.id/files/rpjmn/Narasi RPJMN IV 2020-2024_Revisi 14 Agustus 2019.pdf.

Sitorus, A. V. Y. (2016) 'Dampak Ketimpangan Gender terhadap Pertumbuhan Ekonomi di Indonesia (The Impact of Gender Inequality in Economic Growth in Indonesia)', Sosio Informa, 2(1), pp. 89-101. Available at: https://ejournal.kemsos.go.id/index.php/Sosioinforma/article/viewFile/190/440.

Tambunan, T. T. H. (2016) Pembangunan Ekonomi Inklusif. Jakarta: LP3ES.

Tambunan, T. T. H. (2016) Perekonomian Indonesia Era Orde Lama Hingga Jokowi. 3rd edn. Edited by R. Sikumbang. Bogor: Bogor: Ghalia Indonesia.

Todaro, M. P. and Smith, S. C. (2003) Pembangunan Ekonomi di Dunia Ketiga. 8th edn. Edited by W. C. Kristiaji. Jakarta: Erlangga.

United Nation Development Programme (UNDP) (2015) Sustainable Development Goals. Available at: https://www.undp.org/content/undp/en/home/sustainable-development-goals.html (Accessed: 24 September 2020).

Vininda, S. and Yuliana, L. (2015) 'Penerapan Regresi Data Panel Pengaruh Kesetaraan Gender terhadap Pertumbuhan Ekonomi di Provinsi Riau Periode 2011-2015', Seminar NasionalOfficial Statistics 2019:Pengembangan Official Statistics dalam mendukung Implementasi SDG's, 2015, pp. 549-559. Available at: https://prosiding.stis.ac.id/index.php/semnasoffstat/article/view/416/145.

World Economic Forum (2020) Global Gender Gap Report 2020. Available at: http://www3.weforum.org/docs/WEF_GGGR_2020.pdf. 